\title{
Exploring the relationship between social media usage and academic performances
}

\author{
Udbhava Rathi ${ }^{1 *}$, Daniel John K J ${ }^{2}$, Joel Mathew Jose ${ }^{3}$
}

\section{ABSTRACT}

Social media and academic grades are two of the most important things in an average student's life. Several factors play an important role in determining whether he achieves first class, second class, third class, or distinction. This study aims to find out the extent to which Social Media impacts the student's academic results. Using Pearson's Correlation test, the study determined that there was a negative impact of social media usage on academic performance. Furthermore, Pearson's Correlation test also showed us that the distraction caused by social media impact their academic performance. There is a high need to include various beneficial aspects of social media in a classroom's teachings. Instead of outright condemning social media usage by students, education systems and academics should try and make it a part of the educational curriculum. The longer the academicians try and stick to the age-old teaching method from a constraint boundary of class and books, the more we unequip students from the necessary skillsets required to bring a change and lead.

\section{Keywords: Academic Performance, Social Media, Students, Distractions}

7 Doday Social Media has taken over all aspects of our lives. What started as a medium of connectivity now can shape our opinions. Various entrepreneurs have launched successful businesses standing on the back of social media. Today social media has given individuals the power to create content and absorb it at an increasingly fast rate. Social Media is defined as "forms of electronic communication (such as websites for social networking and microblogging) through which users create online communities to share information, ideas, personal messages, and other content (such as videos)" (Social Media, 2020). With almost every aspect of our lives being influenced by social media, it comes as no surprise that social media impacts education. Since social media has become an intrinsic part of a student's life, it affects the way they think and behave and how it affects their academics.

\footnotetext{
${ }^{1}$ Bachelors of Business Administration student, CHRIST (Deemed to be University), Hosur Road, Bangalore, Karnataka, India

${ }^{2}$ CAPS Coordinator, CHRIST (Deemed to be University), Hosur Road, Bangalore, Karnataka, India

${ }^{3}$ M.Sc. Clinical psychology student, CHRIST (Deemed to be University), Hosur Road, Bangalore, Karnataka, India *Responding Author
}

Received: November 26, 2020; Revision Received: December 18, 2020; Accepted: December 31, 2020

(C) 2020, Rathi U., Daniel John K J \& Jose J.M.; licensee IJIP. This is an Open Access Research distributed under the terms of the Creative Commons Attribution License (www.creativecommons.org/licenses/by/2.0), which permits unrestricted use, distribution, and reproduction in any Medium, provided the original work is properly cited. 


\section{Exploring the relationship between social media usage and academic performances}

Social media also exposes students to a whole new way of learning. Research has shown that frequent social media users are more innovative and exhibit better memory. It opens up new avenues for researching, encouraging students to get creative and think outside the box. (Social Media and its impact on student life, n.d.) Considering how social media connects various people across the globe, we can see how it has been added and proved to benefit students if used in adequate amounts and at appropriate times. It serves as a diverse platform for recent studies' ideas and developments, thereby providing a wide scope for research. Alongside the positives, social media, like any other technological advancement, comes with its downsides, mental health issues, lack of focus, cyberbullying, among various others. However, like any other asset, it depends on our usage and how we, as individuals, can inculcate positive habits revolving around the right consumption of social media content. Honing the art of time management plays a vital role in social media in a student's life. A student must know to decipher the amount of time that can be spent fruitfully on a social media platform that can add value to a student's life, both personally and professionally.

\section{REVIEW OF LITERATURE}

This study researched what students in the undergraduate courses in college feel towards social media employment. Furthermore, it tested the relationship of students' employment of social media with the purpose it has been used and their GPA. The study sought to understand which social media apps were the most used by students: YouTube leading with $33 \%$. Through social media, students can share and interact with their colleagues, benefit from tutorials, and connect with experts on various topics via the internet (Al-Khalifa \& Garcia, 2013). Now, social media has become an integral part of students' lives, so institutions worldwide have adopted social media to convey their students' messages. Some institutes have chosen to stay with the existing ones, such as Facebook; others have created their social media platforms. Institutions also use media for marketing their courses, make an announcement, and interact with their students (Porter, 2013). This study aims to prove that excessive use of social media can affect the academic performances of students. They used primary data in the form of a questionnaire to collect the data. Students from various years, mainly first, second, third, and fourth, were selected for responses. The study concludes that extreme social media use with no authentic supervision from educators or accurate planning to employ its applications may affect undergraduate students' academic performances. Such technologies that are recently widely used among students should be incorporated besides active learning approaches such as problem-based learning, collaborative learning, and flipped classroom as supplementary tools to promote learning outcomes. Students additionally should be directed and learned how to manage their times properly when using social media for educational purposes (Alamari, 2019).

The limitations of the study are that it is country-specific. Social Media usage varies from country to country, so the conclusion, if a similar study is conducted, will also vary from country to country. This can be eliminated if various universities from around the world come together to participate in the study. Another limitation is the number of respondents. Since it is well established social media usage is increasing every year, more students from more varied backgrounds should have been included in the study.

Drury (2008) defined social media as "online resources that people use to share content: video, photos, images, text, ideas, insight, humor, opinion, gossip, news." ICT has been a great tool for revolutionizing our world in the past few decades. Social media usage of generation $\mathrm{Z}$ is linked with their diurnal activities, critical decisions, and performance measures (Tennakoon, Lasanthika, \& Silva, 2019). For instance, career decision making, 


\section{Exploring the relationship between social media usage and academic performances}

matrimonial affairs, learning \& development, entertainment, purchasing, networking, etc. (Valentine, 2018). The authors used a primary source of data, which was collected through the form of a questionnaire. The authors choose three parameters to conduct their research on "time spent, frequency of access and information viewed \& shared" (Tennakoon, Lasanthika, \& Silva, 2019).

The authors used Pearson's correlation to find any relationship between academic performance and time spent on social media. The author found out there was a positive impact of social media on academic performances. But at the same time, countless studies show the contrary point and the mixed point. This leaves the entire research area ambiguous. There is also the fact that this study is geographically constrained as it focuses only on the Sri Lankan students. A wider demographic should be taken to find substantial proof of whether there is any relationship between academic performance and social media usage.

This study's main objective was to find any proof of academic results being impacted by Sri Lankan students' social media usage. The study concluded that all the predetermined parameters affect academic performance and have a moderately positive relationship.

\section{Statement of problem}

Today in a student's life, several factors play an important role in determining whether he achieves first class, second class, third class, or distinction. Some are laid more emphasis on the other. Everyone believes that hard work rewards ultimately. But since times are changing so rapidly, we are in a situation where today's technology is becoming obsolete today. Then comes the aspect of social media. In which a great majority of students are active participants. The advice of deleting social media apps is often handed to students just before their examinations or when preparing for the examination. This study aims to check whether there is a direct correlation between social media usage and the student's academic results.

\section{Objectives of the study}

To determine the relationship between Social Media usage and its impact on the student's academic results.

\section{Scope of the study}

The interest in social media and its impact on students' academic performance has been there for the last decade and is now rising. This is because social media has proved to everyone that it is here to stay. Another factor is the fact that almost all students have a social media presence. There are so many questions yet to be answered, creating knowledge gaps. The research will provide a framework for understanding whether social media has any role in a student's academic result.

\section{Variables}

Independent - Social Media usage by the Students

Dependent- Academic Results achieved by the Students

\section{Hypothesis}

Null hypothesis (Ho): There is no significant impact of social media and academic results on a student

The alternative hypothesis (H1): There is a significant impact of social media on academic results. 


\section{Exploring the relationship between social media usage and academic performances}

\section{Model}

\begin{tabular}{|c|c|}
\hline $\begin{array}{c}\text { STUDENTS USE } \\
\text { OF SOCIAL } \\
\text { MEDIA }\end{array}$ & $\begin{array}{c}\text { STUDENTS } \\
\text { ACADEMIC } \\
\end{array}$ \\
RESULTS \\
\hline
\end{tabular}

\section{METHODOLOGY}

Sample

The research uses a convenience sampling because of the requirement of the study as well as the researcher. Convenience sampling is a sampling method where the population is chosen on how accessible they were to the researcher. The respondents are all college-going students. The sample size of the research is 60 respondents.

\section{Instruments}

The statistical tool used for this study for analyzing the data collected is through SPSS software. The research uses both descriptive and inferential statistics. The inferential statistical tool which is used for analyzing the data collected is a correlation. Descriptive tools like frequency tests are used in this research.

The research uses tables and charts for a better understanding of the data collected. Google forms, through which the primary data was collected, provide the respondents' answers in the form of charts, which helps in the analysis of data.

\section{Type of measurement scale:}

Interval Scale: Interval scales are numeric scales in which we know the order and the exact differences between the values. For our questionnaire, we have used an interval scale that includes both nominal and ordinal scale features, for example, for most of our questions, such as gender selection (male or female) and the yes or no questions. The nominal scale is used because the answers to these questions are not based on any numbers and are very basic. We have also used an interval scale of measurement to get the average number of hours a student uses social media. Here, the person will not specify the exact number of hours but an approximate number that lies in the interval of numbers provided in the options. This scale will help us in knowing the difference between the various values of items. It will also help us calculate various statistical values such as mean, median, and mode.

\section{RESULTS}

\section{Gender of respondents}

Table 1 Gender of respondents

\begin{tabular}{lll} 
Gender & No. of responses & Percentage of responses \\
\hline Female & 58 & $58 \%$ \\
Male & 42 & $42 \%$ \\
\hline
\end{tabular}

Source: Primary data 


\section{Chart 1. Gender of respondents}

Gender?

60 responses

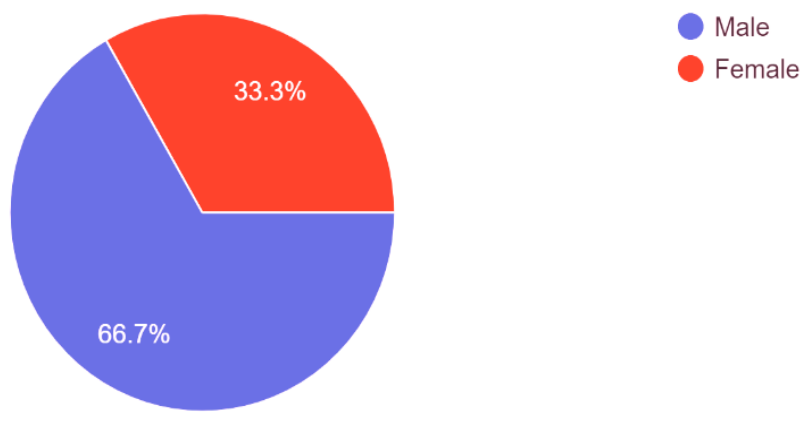

Inference: As per the survey results, $66.7 \%$ of the respondents were males, whereas the remaining $33.3 \%$ were females.

2 Which Social Media apps do you use the most?

Table 2 Reliable source

\begin{tabular}{lll}
\hline Source & No. of responses & Percentage of responses \\
\hline Facebook & 18 & $30 \%$ \\
Instagram & 56 & $93.3 \%$ \\
Tumblr & 6 & $10 \%$ \\
Twitter & 10 & $16.7 \%$ \\
Reddit & 7 & $11.7 \%$ \\
Snapchat & 18 & $30 \%$ \\
Pinterest & 10 & $16.7 \%$ \\
\hline
\end{tabular}

Source: Primary data

\section{Graph 2. Reliable Source}

Which Social Media apps do you use the most?

60 responses

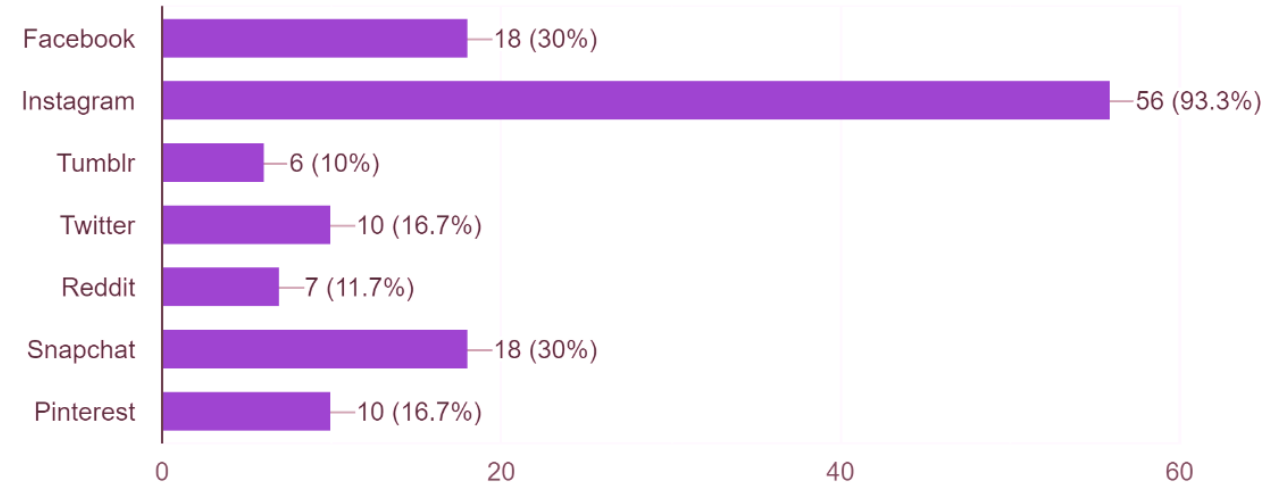

Inference: When asked about the most used social media app, Instagram was seen as the most used app, with $93.3 \%$ of respondents using this the most, after which Facebook and Snapchat have the highest frequency of usage, with $30 \%$ of the respondents using these the 


\section{Exploring the relationship between social media usage and academic performances}

most. Twitter and Pinterest were used after that by $16.7 \%$ of the respondents, Reddit by $11.7 \%$, and Tumblr by the lowest percent, consisting of $10 \%$ of the respondents.

\section{How much time do you spend on Social Media daily?}

\section{Table 3. Time spent on social media}

\begin{tabular}{lcl}
\hline Time & No. of responses & Percentage of responses \\
\hline Less than 1 hour & 7 & $11.7 \%$ \\
1-2 Hours & 17 & $28.3 \%$ \\
2-3 Hours & 15 & $25 \%$ \\
3-4 Hours & 9 & $15 \%$ \\
4-5 Hours & 8 & $13.3 \%$ \\
More than 5 hours & 4 & $6.7 \%$ \\
\hline
\end{tabular}

Source: Primary data

\section{Chart 3.}

How much time do you spend on Social Media on a daily basis?

60 responses
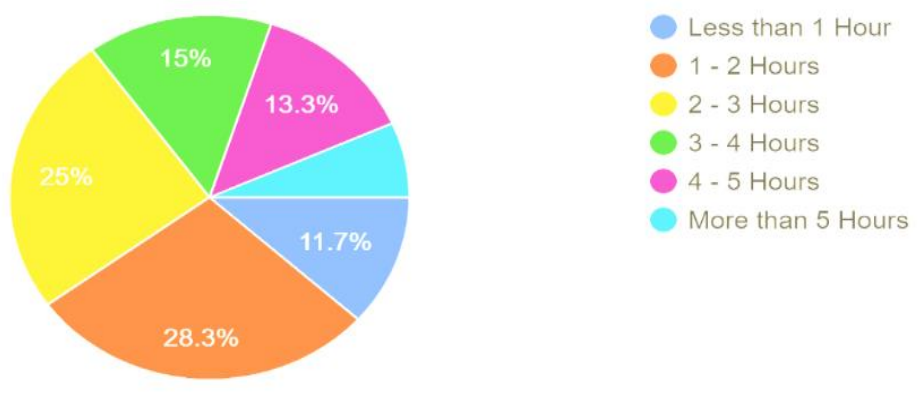

Inference: This graph shows that only $11.7 \%$ of the respondents spend less than an hour per day on Social media. The majority of people spend 1-2 hours on Social media daily, comprising of $28.3 \%$ of the respondent population, subsequently followed by $25 \%$ spending 2-3 hours, $15 \%$ with 3-4 hours, and $13.3 \%$ spending a staggering 4-5 hours every day on Social Media. The lowest percentage spend more than 5 hours a day on Social media.

\section{How often do you get distracted while doing your work or assignment?}

Table 4. distracted while doing your work or assignment

\begin{tabular}{lll}
\hline Frequency of Distraction & No. of responses & Percentage of responses \\
\hline Always & 21 & $35 \%$ \\
Once in a while & 37 & $61.7 \%$ \\
Never & 2 & $3.3 \%$ \\
\hline
\end{tabular}

Source: Primary data 


\section{Exploring the relationship between social media usage and academic performances}

\section{Chart 4.}

How often do you get distracted while doing your work or assignment?

60 responses

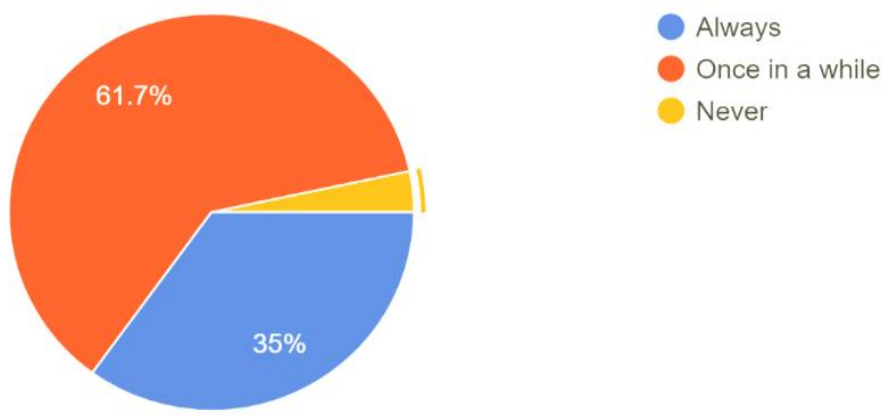

Inference: This graph shows that the students do not always get distracted by Social Media. Only $35 \%$ of the respondents always get distracted. Whereas the majority of them, comprising of $61.7 \%$, said that they get distracted only once in a while, followed by the lowest percent never getting distracted by social media.

5. How often do you discuss studies and work related to academics over social media? Table 5. Suggestion from peers for selection of restaurants

\begin{tabular}{lll}
\hline Suggestion from peers & No. of responses & Percentage of responses \\
\hline All the work / Always & 9 & $15 \%$ \\
Some of the work / Sometimes & 44 & $73.3 \%$ \\
None of the work / Never & 7 & $11.7 \%$ \\
\hline
\end{tabular}

Source: Primary data

\section{Chart 5.}

How often do you discuss studies and work related to academics over social media? 60 responses

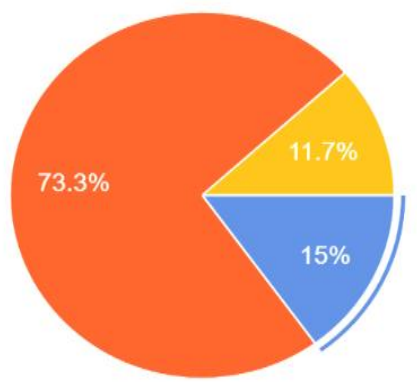

Inference: The majority of the respondents, i.e., $73.3 \%$, are seen to discuss study and work related to academics over social media only sometimes. $15 \%$ always discuss work and academics on social media, leaving the rest of $11.7 \%$ of respondents who never discuss work and academics on Social media. 


\section{Exploring the relationship between social media usage and academic performances}

6. What time of the day do you use social media the most?

Table 6 Time of the day

\begin{tabular}{lll}
\hline Time of the day & No. of responses & Percentage of responses \\
\hline Morning & 0 & $0 \%$ \\
Afternoon & 5 & $8.3 \%$ \\
Evening & 17 & $28.3 \%$ \\
Night & 38 & $63.3 \%$ \\
\hline
\end{tabular}

Source: Primary data

\section{Chart 6.}

What time of the day do you use social media the most?

60 responses

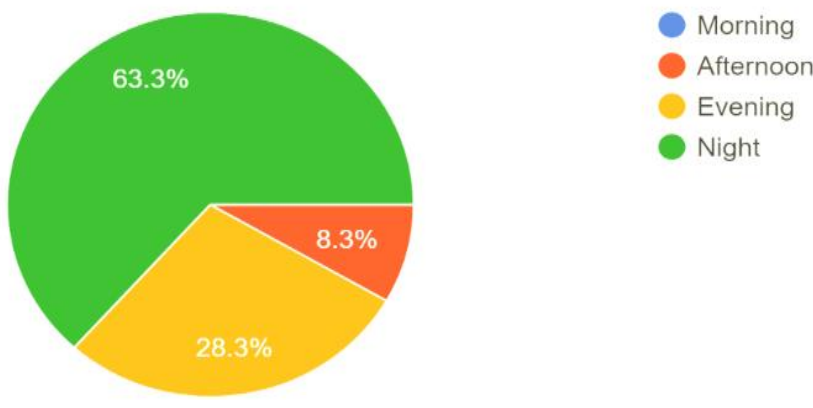

Inference: A large percent of the respondents spend the most time in the night on social media, i.e., $63.3 \%$. $28.3 \%$ of them spend the most time in the evening whereas $8.3 \%$ spend the most time in the afternoon. None of the respondents spend any time on social media in the morning.

7. Does your Social Media usage decrease during the exam period?

Table 7. Social Media usage decrease during the exam period

\begin{tabular}{lll}
\hline & No. of responses & Percentage of responses \\
\hline Yes & 37 & $61.7 \%$ \\
No & 23 & $38.3 \%$ \\
\hline
\end{tabular}

Source: Primary data

\section{Chart 7.}

Does your Social Media usage decrease during the exam period?

60 responses

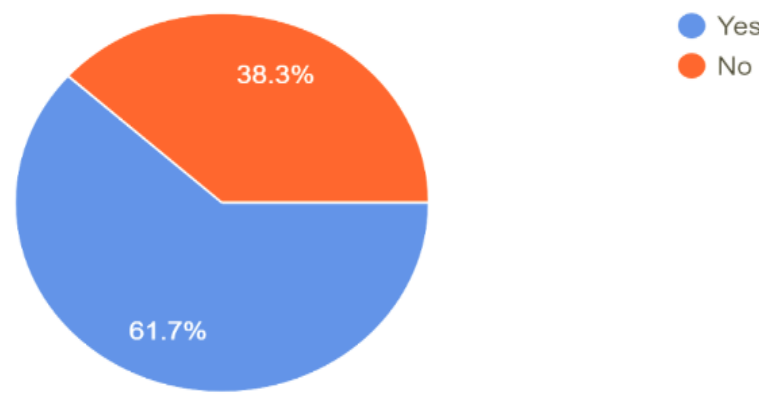

C The International Journal of Indian Psychology, ISSN 2348-5396 (e)| ISSN: 2349-3429 (p) | 1225 


\section{Exploring the relationship between social media usage and academic performances}

Inference: According to the graph, $61.7 \%$ of the students decrease their usage on social media during the exam period, leaving the rest $38.3 \%$ of them who do not decrease their usage on social media during the exam period.

\section{What is your Academic Performance?}

Table 8. Academic Performance

\begin{tabular}{lll}
\hline Academic Performance & No. of responses & Percentage of responses \\
\hline Distinction & 15 & $25 \%$ \\
First Class & 34 & $56.7 \%$ \\
Second Class & 10 & $16.7 \%$ \\
Third Class & 1 & $1.7 \%$ \\
\hline
\end{tabular}

Source: Primary data

\section{Chart 8.}

What is your Academic Performance?

60 responses

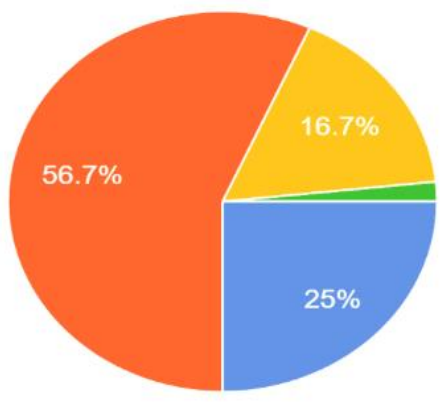

Distinction

First Class

Second Class

Third Class

Inference: The majority of the respondents have attained first class in their academic records, followed by $16.7 \%$ Second class performers. $25 \%$ of the respondents have attained distinction, and the least percent have a third class.

Table 9. Relationship between Academic Performance and Time Spent on Social Media Correlations

\begin{tabular}{llll}
\hline & & $\begin{array}{l}\text { Academic } \\
\text { Performance }\end{array}$ & $\begin{array}{l}\text { Time spent on } \\
\text { Social Media }\end{array}$ \\
\hline \multirow{3}{*}{ Academic Performance } & Pearson Correlation & 1 & $-.282^{*}$ \\
& Sig. (2-tailed) & 60 & .029 \\
& $\mathrm{~N}$ & $-.282^{*}$ & 60 \\
\multirow{2}{*}{ Time spent on Social Media } & $\begin{array}{l}\text { Pearson Correlation } \\
\text { Sig. (2-tailed) }\end{array}$ & .029 & 1 \\
& $\mathrm{~N}$ & 60 & 60 \\
\hline
\end{tabular}

*. Correlation is significant at the 0.05 level (2-tailed).

Note: There exists a negative correlation between time spent on social media and academic performance. A negative correlation implies that if one variable increases, the other decreases. This means if we increase our social media using our academic results will decrease. We have taken the value of $\mathrm{P}$ as 0.05 . If the correlation value is above 0.05 , we accept the Null Hypothesis. But our value -.282, which is less than 0.05, therefore we failed to accept the null hypothesis or reject the null hypothesis. 
Table 10. Relationship between Academic Performance and Distraction Caused by Social Media

\begin{tabular}{llll}
\hline & & $\begin{array}{l}\text { Academic } \\
\text { Performance }\end{array}$ & $\begin{array}{l}\text { Distractions } \\
\text { caused by Social } \\
\text { Media }\end{array}$ \\
\hline \multirow{2}{*}{ Academic Performance } & Pearson Correlation & 1 & .002 \\
& Sig. (2-tailed) & 686 \\
Distractions caused by Social Media & $\mathrm{N}$ & 60 & 60 \\
& Pearson Correlation & .002 & 1 \\
& Sig. (2-tailed) & .986 & \\
& $\mathrm{~N}$ & 60 & 60 \\
\hline
\end{tabular}

There exists a weak positive relationship between academic performance and distractions caused by social media. But at the same time, we have accepted the value of $\mathrm{P}$ to be as 0.05 , and over here, the correlation value is .002. This is lesser than the significant value of 0.05 , which means we fail to accept the null hypothesis or reject the null hypothesis; thus, the alternate hypothesis is accepted.

\section{DISCUSSION}

This chapter describes how the objectives are achieved through primary data, which are collected through a questionnaire. The findings of the study are:

- As per the results of the survey conducted, $66.7 \%$ of the respondents were males, whereas the remaining $33.3 \%$ were females

- When asked about the most used social media app, Instagram was seen as the most used app, with $93.3 \%$ of respondents using this the most after which, Facebook and Snapchat have the highest frequency of usage, with $30 \%$ of people using these the most. Twitter and Pinterest were used the most by $16.7 \%$ of people, Reddit by $11.7 \%$, and Tumblr by the lowest percent, consisting of $10 \%$.

- Only $11.7 \%$ of the respondents spend less than an hour per day on Social media. The majority of people spend 1-2 hours on Social media daily, comprising of $28.3 \%$ of the respondent population, subsequently followed by $25 \%$ spending $2-3$ hours, $15 \%$ with 3-4 hours, and $13.3 \%$ spending a staggering 4-5 hours every day on Social Media. The lowest percentage spend more than 5 hours a day on Social media.

- We learned from our survey students do not always get distracted by Social Media. Only $35 \%$ of the respondents always get distracted. Whereas the majority of them, comprising of $61.7 \%$, said that they get distracted only once in a while, followed by the lowest percent never getting distracted by social media.

- The majority of the respondents, i.e., $73.3 \%$, are seen to discuss study and work related to academics over social media only sometimes. $15 \%$ always discuss work and academics on social media, leaving the rest $11.7 \%$ of respondents who never discuss work and academics on Social media

- A large percentage of the respondents spend the most time in the night on social media, i.e., $63.3 \%$. $28.3 \%$ of them spend the most time in the evening whereas $8.3 \%$ spend the most time in the afternoon. None of the respondents spend any time on social media in the morning.

- Another thing we learned was that $61.7 \%$ of the students do decrease their usage on social media during the exam period, leaving the rest $38.3 \%$ of them who do not decrease their usage on social media during the exam period 


\section{Exploring the relationship between social media usage and academic performances}

- The majority of the respondents have attained first class in their academic records, followed by $16.7 \%$ Second class performers. $25 \%$ of the respondents have attained distinction, and the least percent have a third class.

- After running the Pearson's correlation test, we realized a negative correlation between academic performance and time spent on social media. A negative correlation implies that if one variable increases, the other decreases. This means if we increase our social media using our academic results will decrease.

- After running the Pearson's correlation test, there is a weak positive relationship between academic performance and social media distractions.

\section{Suggestions}

The study found out that social media usage has a significant impact on a student's academic performance. The more time a student spends on social media, the lesser he or she scores academically. This has to serve as a wake-up call for both the students and the academicians as well. There is a high need to include various beneficial aspects of social media in a classroom's teachings. The longer the academicians try and stick to the age-old teaching method from a constraint boundary of class and books, the more we unequip students from the necessary skillsets required to bring a change and lead. A middle ground needs to be developed where social media can benefit both the teachers and the students.

\section{CONCLUSION}

This study aimed to find the impact of social media usage by students on their academic performance. There is a vast amount of research surrounding students' social media usage and its impact on academic performance, but not specifically in South Bangalore. The objectives of the study were achieved by having a sample filling a brief questionnaire. The study's findings and implications cannot be generalized to Bangalore's population, as this covers only respondents from South Bangalore.

Further research can be done on this topic using a larger sample and concentrating on different geographical locations. A wider demographic should be taken to find substantial proof of whether there is any relationship between academic performance and social media usage. Furthermore, this study has only taken academic performance based on the distinction, etc., derived from Grade Point Average. But it does not include various soft skills that can be learned through social media.

\section{REFERENCES}

Alamari, M. M. (2019). Udergraduate Students' Perception towards Social Media Usage and Academic Performance: A Study from Saudi Arabia . iJET - Vol 14, No. 3.

Al-Khalifa, H. S., \& Garcia, A. R. (2013). The state of social media in Saudi Arabia's higher education. International Journal of Technology and Educational Marketing (IJTEM), $3,65-76$.

Drury, G. (2008). Social media: Shoul marketers engage and how it can be done effectively. Journal of Direct, Data and DIGITAL marketing Practices, 9, 274-277.

Social Media. (2020, January 27). Retrieved from Merriam-Webster: https://www.merriamwebster.com/dictionary/social\%20media

Social Media and its impact on student life. (n.d.). Retrieved from https://www.studentjob.co.uk/blog/1833-social-media-and-its-impact-on-student-life

Tennakoon, Lasanthika, \& Silva. (2019). Impact of Social Media usage on academic performance: A case of undergraduates in Sri Lankan state universities. 


\section{Exploring the relationship between social media usage and academic performances}

Valentine, O. (2018). Chart of the day. Retrieved from Global Bindex: 2018 https://blog.globalwebindex.com/chart-of-the-day/gen-z-now-spend-4-hours-dailyonline-via-mobile/

\section{Acknowledgement}

This paper would not have been complete without the support of Mr. Daniel John who guided the authors and kept the entire process on track. The authors are indebted to their families and friends for their constant support, reviews and comments.

\section{Conflict of Interest}

The author declared no conflict of interest.

How to cite this article: Rathi U., Daniel John K J \& Jose J.M. (2020). Exploring the relationship between social media usage and academic performances. International Journal of Indian Psychology, 8(4), 1218-1229. DIP:18.01.133/20200804, DOI:10.25215/0804.133 